\title{
Establishment of a Real-time RT-PCR Assay for Avian Encephalomyelitis Virus
}

\author{
QINGHONG XUE, HUI GUO, ZHONGZE FENG, JIA WANG
}

China Institute of Veterinary Drug Control, No. 8 Zhongguancun South Street, Beijing 100081, China

\section{Xue Q., Guo H., Feng Z., Wang J. \\ Establishment of a Real-time RT-PCR Assay for Avian Encephalomyelitis Virus}

\section{Summary}

Avian encephalomyelitis is an epidemic disease caused by avian encephalomyelitis virus (AEV), which exerts egg drop, slow growth, decreased egg hatchability, rapid tremors and ataxia of the head and neck in chicks and laying hens. The availability of a robust diagnostic assay to confirm the infection of AEV is important for its prevention and control. Thus, this study aimed to develop and validate a rapid Real-time RT-PCR assay for the detection and quantification of AEV. The authors developed and validated a TaqMan-based fluorescent real-time RT-PCR with sensitivity, specificity and reproducibility for rapid detection of EAV. This assay was then applied on 52 clinical samples from 37 suspected chickens. The minimal detection limit of this method was 20 copies. No cross-reactivity with Newcastle disease virus (NDV), avian influenza virus (AIV), Marek's disease virus (MDV) or avian leukosis virus (ALV) was observed. The intra- and inter-assay coefficients of variation were both below $2 \%$. Of the 52 clinical samples analyzed using this assay, 33 samples were positive for AEV, yielding an agreement rate of $91.2 \%$ with RT-PCR and $88.2 \%$ with the agar diffusion test. In conclusion, we have successfully developed and validated a sensitive Real-time RT-PCR for rapid detection of AEV, which could be used in the early diagnosis, prevention and control, and epidemiological investigation of AEV.

Keywords: Avian encephalomyelitis virus, Real-time RT-PCR, diagnosis

Avian encephalomyelitis virus (AEV) is a single-stranded RNA virus of positive polarity belonging to the Picornaviridae family. The virus can cause avian encephalomyelitis (AE) in chicks and laying hens, resulting in egg drop, slow growth, decreased egg hatchability, rapid tremors and ataxia of the head and neck (known as "epidemic tremor") $(2,7,25)$. The vertical transmission of AEV infection can result in severe economic losses. In 1930, Jones reported the first case of AE symptoms in commercially available two-week-old Rhode Island Red chickens (3). AE has been detected worldwide and has a mean mortality rate of $25 \%(18,19)$. In China, AE was first reported in the 1980s in several provinces, such as Heilongjiang, Jiangsu, and Guangdong. Nowadays the Chinese government has demanded that the latest incidences of $\mathrm{AE}$ should be recorded and reported to responsible veterinary departments (20). AEV often induces high morbidity and variable mortality in adult hens. Most recent symptoms are sub-clinical and atypical, which increase the difficulty of diagnosis (21). A reliable detection method of AEV is critical for the case confirmation and prevention of this disease. Therefore, a sensitive, specific, and rapid detection method is extremely important for the prevention, control and surveillance of $\mathrm{AE}$ and for public health safety. The current detection methods for AEV contain etiological and serological methods. Etiological methods generally include virus isolation and identification $(14,26,32)$ and indirect fluorescent antibody test $(1,24)$, while serological methods include chick embryo assay (30), indirect fluorescent antibody test (8), immunodiffusion test $(12,17,22)$ and enzyme linked immunosorbent assay $(11,29,31)$. Molecular biology-based tests have become essential, particularly for the detection of newly emerging viruses or for those that cannot be confirmed by conventional methods. In this study, we attempted to establish a novel TaqMan-based real-time fluorescent RT-PCR method for the detection of AEV. Compared with conventional methods, this new technique is rapider and more sensitive. Therefore it is suitable for the detection of AEV in clinical samples and laboratory materials. It can remarkably improve clinical detection and monitoring of $\mathrm{AE}$ and consequently enhance the prevention and control of this disease. 


\section{Material and methods}

Cell line and viruses. The following five virus strains were used for specificity evaluation in this study, including Newcastle disease virus (NDV) strain CS2, Avian influenza virus (AIV) strain H5N1 Re-6, Marek's disease virus (MDV) strain FC-126, Avian leucosis virus (ALV) strains RAV1 and RAV2 and AEV strains 001 and 002 were kindly provided by Prof. Zhang Shuxia from Northwest A\&F University. Chicken embryo fibroblast (CEF) was maintained in Dulbecco's modified Eagle's medium (DMEM) (Life Technologies, USA), supplemented with $10 \%$ fetal bovine serum (FBS) (Life Technologies, CA, USA) at $37^{\circ} \mathrm{C}$ with $5 \% \mathrm{CO}_{2}$. All viruses were passaged in CEF cells or embryonated eggs for 3-5 days to produce the final virus stocks. Briefly, a monolayer of CEF cells or embryonated egg was infected with the aforementioned viruses until $75 \%-100 \%$ cytopathic effect (CPE) was observed. The viral culture supernatants were collected and stored at $-80^{\circ} \mathrm{C}$ until required. All experiments with live AEV were performed in biosafety level 2 laboratories.

Field samples. Fifty-two clinical samples (brain, pancreas, liver, duodenum and feces) were obtained from 37 chickens at two weeks suspected of AE from two farms in Hebei province. Negative control samples (including the brain, pancreas, liver, duodenum, and feces) were obtained from Specific Pathogen-Free (SPF) chickens purchased from Beijing Meili Avignon Laboratory Animal Technology Co., Ltd. A 10\% suspension was made from homogenized samples in DMEM (Life Technologies, CA, USA). After centrifugation at $10,000 \mathrm{~g}$ for 10 minutes, the upper suspension was collected for further analysis. The field studies were approved by each farm, and the field samples were appropriately coded for anonymity. All animal experiment procedures were carried out in strict accordance with the guidelines of the Animal Experiment Committee.

RNA extraction. Total RNA was extracted from virus infected supernatants and clinical samples using the viral RNA kit (Omega Bio-tek, USA), according to the manufacturer's instructions. RNA were eluted in a $50 \mu \mathrm{L}$ elution buffer and stored at $-80^{\circ} \mathrm{C}$ until required.

Primer design for real-time RT-PCR. The nucleotide sequences of the complete genome of AEV strain van Roekel (GenBank: AY517471) and L2Z (GenBank: AY275539) were retrieved from the GenBank database. The primers for the AEV-specific Real-time RT-PCR assay were designed using Primer Express 3.0 software (Applied Biosystems $\left.{ }^{\circledR}\right)$. Four primer sets were screened and validated using the BLAST program. After evaluation with different dilutions of AEV viral RNA, the optimum primer pair was screened. All of the primers used in this study (Tab. 1) were synthesized by Invitrogen Ltd. (Shanghai). Nucleotide

Tab. 1. Primers and probe

\begin{tabular}{|l|l|}
\hline \multicolumn{1}{|c|}{ Primers/Probe name } & \multicolumn{1}{c|}{ Primers/Probe sequences (5'-3') } \\
\hline AEV-Forward & AAACATCGGTAGGTGCCATTA \\
\hline AEV-Reverse & CAGTGGCGTGTAGAAAGGGA \\
\hline AEV-Probe & FAM-TAATACTGGACAAACTAC-TAMRA \\
\hline
\end{tabular}

sequence (489-793 nt, artificially synthesized by Taihegene, China) of AEV strains was ligated to T-EASY vector (Promega, USA) to generate the recombinant plasmid AEV-P. The recombinant plasmid was measured and adjusted to a concentration of $10^{8}$ copies $/ \mu \mathrm{L}$ and then stored at $-20^{\circ} \mathrm{C}$ until required.

RT-PCR. The conventional RT-PCR reaction was performed using PrimeScript One-Step RT-PCR Kit (Takara, Dalian, China) with AEV specific primers TV-3(f) and TV-3(r) as described previously by Choi et al. (8). The primers amplified a 400-bp segment of the envelope gene of the AEV genome. The $50 \mu \mathrm{L}$ reaction mixture contained $2 \mu \mathrm{L}$ of total RNA, $25 \mu \mathrm{L}$ of $2 \times$ One step buffer, $2 \mu \mathrm{L}$ of PrimeScript One Step Enzyme Mix, $2 \mu \mathrm{L}$ each of forward and reverse primer $(10 \mu \mathrm{M})$, and $17 \mu \mathrm{L}$ of RNase-free water. The reaction conditions were as follows: $50^{\circ} \mathrm{C}$ for $30 \mathrm{~min}$ and $94^{\circ} \mathrm{C}$ for $2 \mathrm{~min}$, followed by 35 cycles of $94^{\circ} \mathrm{C}$ for $30 \mathrm{sec}, 55^{\circ} \mathrm{C}$ for $30 \mathrm{sec}$ and $70^{\circ} \mathrm{C}$ for $30 \mathrm{sec}$, with a final extension step of $72^{\circ} \mathrm{C}$ for $10 \mathrm{~min}$. The RT-PCR products were analyzed by agarose gel electrophoresis.

Real-time RT-PCR. Real-time RT-PCR was performed using GoldStarTaqMan Mixture (CW-BIO, Beijing, China) in the Light Cycler 2.0 system (Roche, Penzberg, Germany). The $20 \mu \mathrm{L}$ reaction mixture contained $2 \mu \mathrm{L}$ total RNA, $10 \mu \mathrm{L}$ GoldStarTaqMan Mixture Buffer, $1.2 \mu \mathrm{L}$ Ex Taq HS mix, $0.4 \mu \mathrm{L}$ PrimeScript PLUS RTase Mix (TAKARA, Dalian, China), $0.8 \mu \mathrm{L}$ each of forward and reverse primer $(10 \mu \mathrm{M})$, and $4.8 \mu \mathrm{L}$ RNase-free water. The matrix method was used to determine the optimum reaction conditions and was carried out at $42^{\circ} \mathrm{C}$ for $5 \mathrm{~min}$, followed by $20 \mathrm{sec}$ at $95^{\circ} \mathrm{C}$, with a subsequent 40 cycles of amplification $\left(95^{\circ} \mathrm{C}\right.$ for $5 \mathrm{sec}$ and $60^{\circ} \mathrm{C}$ for $20 \mathrm{sec}$, fluorescence was recorded at $60^{\circ} \mathrm{C}$ ). This was followed by a melting analysis cycle $\left(95^{\circ} \mathrm{C}\right.$ for $5 \mathrm{sec} ; 65^{\circ} \mathrm{C}$ for $15 \mathrm{sec} ; 9^{\circ} \mathrm{C}$ for $15 \mathrm{sec}$ by slowly increasing the temperature $0.1^{\circ} \mathrm{C}$ per second).

Sensitivity and specificity of the assays. The sensitivity of the Real-time RT-PCR assays was assessed against AEV-P from a ten-fold dilution series $\left(10^{1}-10^{7}\right.$ copies $\left./ \mu \mathrm{L}\right)$. The standard curve for the Real-time RT-PCR assay was established by plotting the log of each standard of known concentration in the dilution series against the $\mathrm{Ct}$ values for the corresponded concentration. The specificity of this assay was evaluated by a cross-reactivity test with five other related members of the virus genus including NDV strain CS2, AIV strain H5N1, MDV strain FC-126and ALV strains RAV1 and RAV2.

Reproducibility of the Real-time RT-PCR. Four AEV samples with different virus titers were obtained. RNA was extracted three times at different time points for testing, and then the inter-lot repeatability test was performed under the same reaction conditions. For the intra-lot repeatability test, three samples underwent four repeatability tests after the RNA was extracted. The reproducibility test was carried out according to optimized reaction conditions of Real-time RT-PCR.

Evaluation with field samples. The Real-time RT-PCR assays were evaluated with 52 field samples; all samples were also tested by conventional RT-PCR assay and sequenced. 


\section{Results and discussion}

Optimized reaction conditions of Real-time RT-PCR. The optimized reaction system for Real-time RT-PCR was as follows: $2.5 \mu \mathrm{L} 10 \times$ reaction buffer, $2 \mu \mathrm{L}$ dNTPs $(2.5 \mathrm{mM}), 4 \mu \mathrm{L} \mathrm{MgCl}(25 \mathrm{mM}), 1 \mu \mathrm{L}$ AEV-Forward $(10 \mu \mathrm{M}), 1 \mu \mathrm{L}$ AEV-Reverse $(10 \mu \mathrm{M})$, $0.2 \mu \mathrm{L}$ AEV-Probe $(10 \mu \mathrm{M})$, and $1.0 \mathrm{IU}$ Hot-start Pfu polymerase. The total reaction volume was made up to $25 \mu \mathrm{L}$ with PCR-grade water after the addition of template. The reaction conditions were $95^{\circ} \mathrm{C}$ for $5 \mathrm{~min}$, $95^{\circ} \mathrm{C}$ for $10 \mathrm{sec}$ and $40 \mathrm{cycles}$ of $60^{\circ} \mathrm{C}$ for $50 \mathrm{sec}$. The final concentration of AEV-P was $0.5 \mu \mathrm{M}$, and the final concentration of $\mathrm{Mg}^{2+}$ was $5 \mathrm{mM}$.

Dynamic and standard curve. Figure 1 represented the dynamic curve for $\mathrm{Ct}$ values of $12.96,16.09,19.43$, $22.82,25.84,29.36,32.85$, corresponding to plasmid concentrations in the order of $10^{1}-10^{7}$ copies $/ \mu \mathrm{L}$. The slope of the standard curve was -3.308 and the intercept was 37.523. A straight line equation was derived in accordance with the above data, which was $y=-3.308 \lg x+37.523$.

The sensitivity and specificity of Real-time RT-PCR. The sensitivity of the real-time RT-PCR assays was analyzed using AEV-P ranging from $10^{1}$ copies $/ \mu \mathrm{L}$ to $10^{7}$ copies $/ \mu \mathrm{L}$ by ten-fold dilution. $2 \mu \mathrm{L}$ of plasmid in each concentration were used in the optimized quantitative fluorescence PCR system with two parallel reactions (Fig. 2A). The curves were basically consistent, and each concentration showed a strong linear relationship with the other concentrations (coefficient of correlation $\mathrm{R}^{2}=0.987$; amplification efficiency $\mathrm{E}=1.0$; and detection limit: 20 copies). No cross reaction with NDV, MDV, AIV, or ALV was observed.

Tests for the repeatability of Real-time RT-PCR. Four AEV samples with different virus titers were obtained. RNA was extracted three times at different time points for Real-time RT-PCR, and then an interlot repeatability test was performed under the same reaction conditions. For the intra-lot repeatability test, three samples underwent four repeatability tests after the RNA was extracted for reverse transcription. The results showed that both the intra- and inter-assay coefficients of variation were below $2 \%$, indicating that this method had good repeatability (Tab. 2).

Tab. 2. Results of reproducible test

\begin{tabular}{|c|c|c|c|c|c|c|c|c|}
\hline \multirow{2}{*}{ 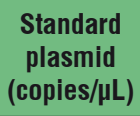 } & \multicolumn{4}{|c|}{ Intra-assay Ct value } & \multicolumn{4}{|c|}{ Inter-assay Ct value } \\
\hline & 1 & 2 & 3 & CV (\%) & 1 & 2 & 3 & CV (\%) \\
\hline $1.0 \times 10^{5}$ & 20.26 & 20.33 & 20.28 & 0.62 & 20.84 & 20.05 & 20.21 & 1.12 \\
\hline $1.0 \times 10^{3}$ & 27.32 & 27.53 & 27.47 & 0.71 & 27.21 & 27.74 & 27.23 & 1.07 \\
\hline $1.0 \times 10^{1}$ & 34.28 & 34.09 & 34.33 & 0.55 & 34.40 & 34.88 & 34.15 & 1.39 \\
\hline
\end{tabular}

Evaluation with field samples. Field samples were tested using both Real-time RT-PCR assays and conventional RT-PCR assays. A comparison of the results

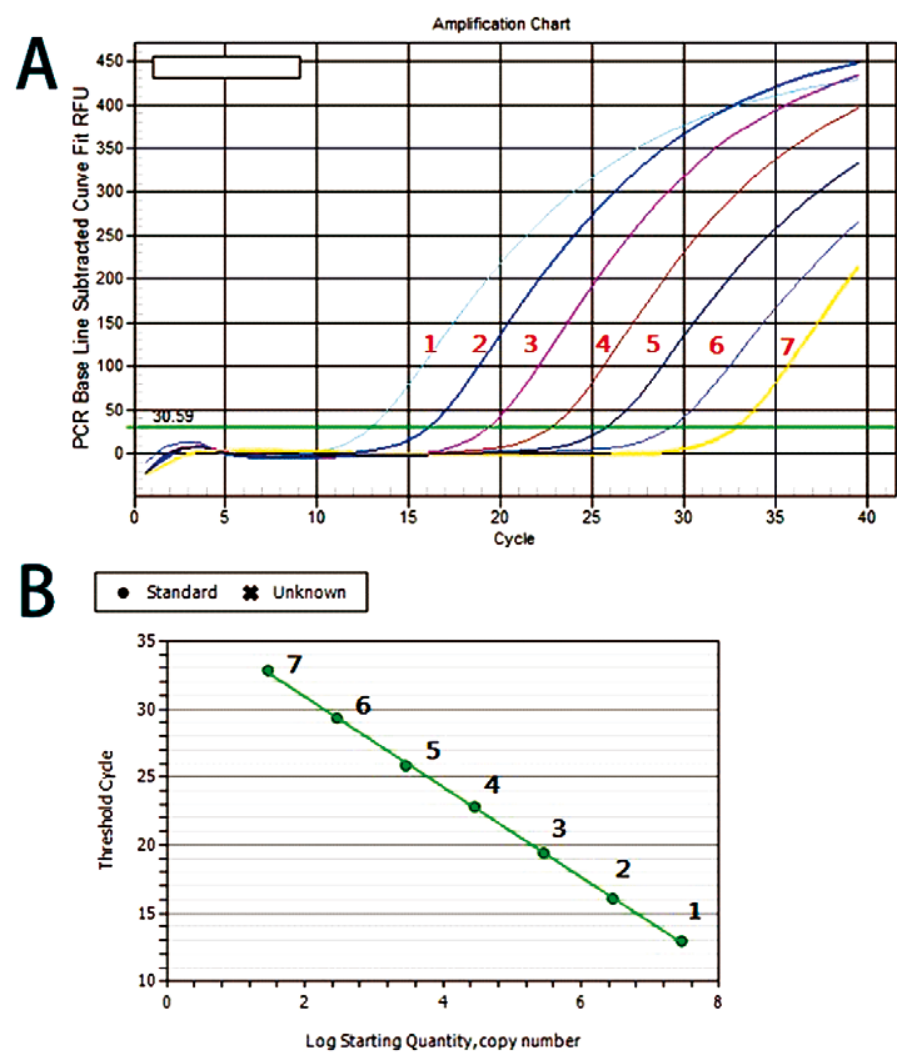

Fig. 1. Dynamic curve of amplification and standard curve Explanations: Dynamic curve of amplification, A. Seven curves (1-7) represent plasmid template with concentrations of $10^{7}-10^{1}$ copies/ $\mu \mathrm{L}$ respectively; B. Standard curve, Seven points (1-7) represent plasmid template with concentrations of $10^{7}-10^{1}$ copies $/ \mu \mathrm{L}$ respectively

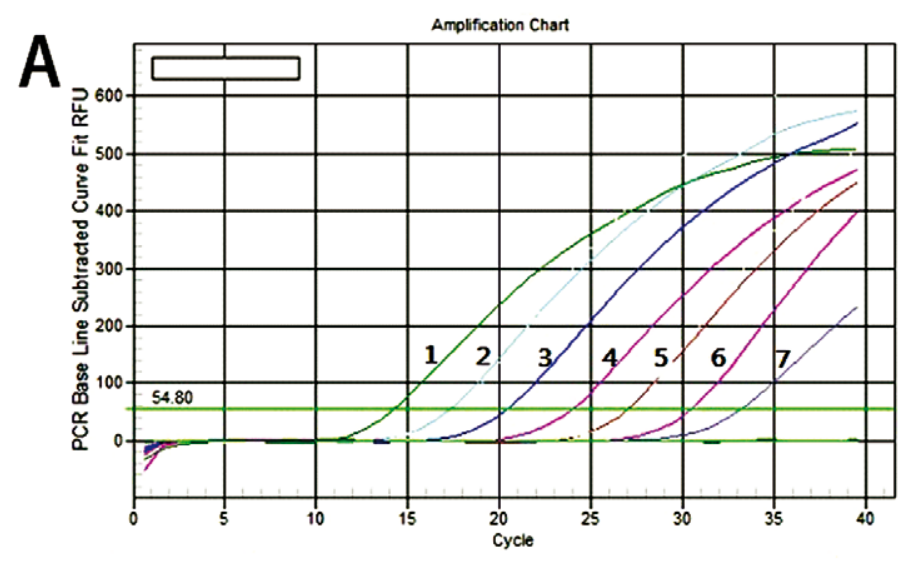

B

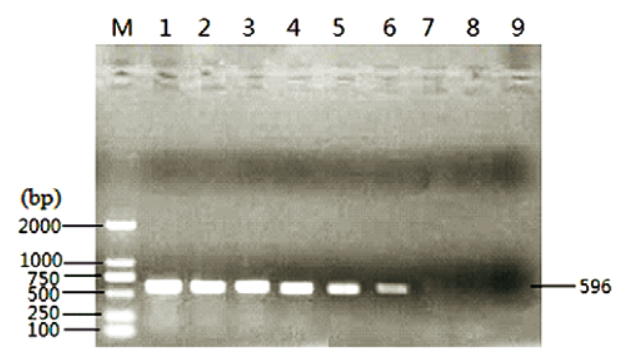

Fig. 2. Sensitivity test of Real-time RT-PCR and conventional RT-PCR

Explanations: A. Seven curves represent plasmid templates with concentrations of $10^{7}-10^{1}$ copies/ $\mu \mathrm{L}$ respectively; B. M stands for standard nucleic acid marker, six channels represent plasmid template with concentration of $10^{6}-10^{1}$ copies $/ \mu \mathrm{L}$ 
Tab. 3. Comparison of RT-PCR and Real-time RT-PCR test for the detection of AEV in field samples

\begin{tabular}{|l|c|c|}
\hline & RT-PCR & Real-time RT-PCR \\
\hline Positive & 31 & $3^{*}$ \\
Negative & 21 & 19 \\
\hline Sensitivity (\%) & $91.2 \%$ & $97.1 \%$ \\
Specificity (\%) & $100 \%$ & $100 \%$ \\
\hline Concordance & $94.2 \%$ & $98.1 \%$ \\
\hline Assay time & 105 minutes & 30 minutes * $^{*}$ \\
\hline
\end{tabular}

Explanations: * $\mathrm{Ct}<37$ cycles; ** By use of the LightCycler 2.0 system

obtained was recorded in Table 3. Samples collected from healthy chicks were all tested as negative for both assays. Of the 52 clinical samples tested, 33 samples were positive for AEV using Real-time RT-PCR, while 31 samples were positive for AEV using conventional RT-PCR, yielding an agreement rate of $91.2 \%$. These results demonstrated that Real-time RT-PCR was more sensitive than conventional RT-PCR.

Comparison of viral loads in different tissues. The viral loads of AEV in five different tissue samples were determined using the Real-time RT-PCR assay. The viral load peak of $3.01 \log 10 \mathrm{PFU} / \mathrm{ml}$ was observed in the brain samples. A median of $2.13 \log 10 \mathrm{PFU} / \mathrm{ml}$ (IQR: 1.79 to $2.69 \log 10 \mathrm{PFU} / \mathrm{ml}$ ) was observed in the pancreas and duodenum samples. A median of 1.86 $\log 10$ PFU/ml (IQR: 0.98 to $2.23 \log 10 \mathrm{PFU} / \mathrm{ml}$ ) was observed in the fecal samples. The viral load median in the liver samples was $0.03 \log 10 \mathrm{PFU} / \mathrm{ml}$ (IQR: -0.74 to $0.56 \log 10 \mathrm{PFU} / \mathrm{ml})$. The results demonstrated that the brain tissues exhibited higher viral loads compared with liver, pancreas, duodenum and fecal samples in AEV-infected chickens.

The non-enveloped AEV particle can survive under a range of external environmental conditions. For instance, it can maintain infective activity for 70 days in dry or freezing conditions, and be transmitted horizontally or vertically $(4,5,13,27)$. Since the majority of $\mathrm{AE}$ cases occur sporadically and have relatively smaller economic costs than Newcastle disease or Marek's disease (16), little attention has been paid to this disease in numerous countries. As a result, AEV has led to certain economic losses by causing reduced hatching rates and characteristic neurological disorders, such as tremors and ataxia in younger chicks. There is no effective treatment for AE. Thus, prevention, management and control of AEV transmission are essential in disease control (28). A rapid and efficient diagnosis method of AEV is critical to achieve this goal.

Antibody detection, virus isolation and conventional RT-PCR are the most common techniques to detect AEV. However, these methods are not feasible in the early identification of this virus. Although virus isolation has been regarded as the golden standard for virus

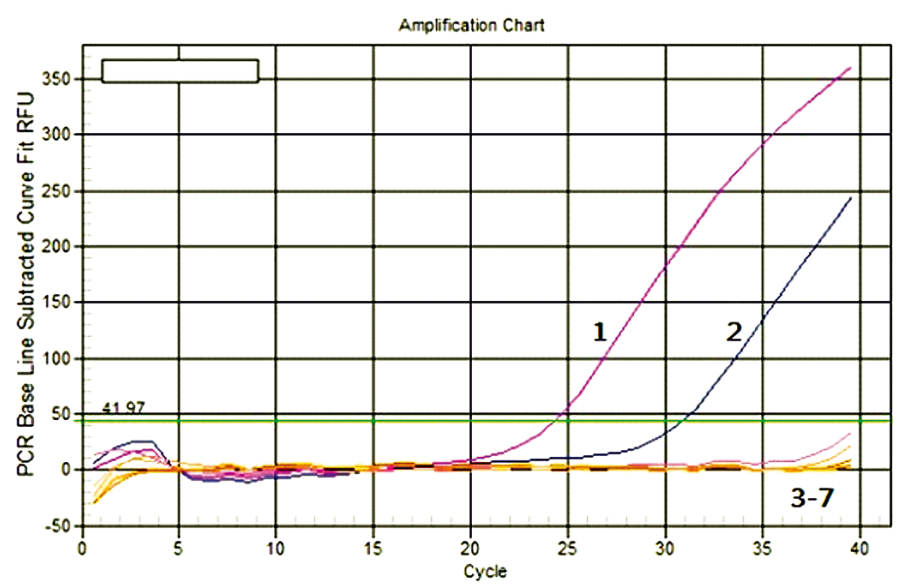

Fig. 3. Specificity test of Real-time RT-PCR

Explanations: Curve 1 represents AEV 001 strain; curve 2 represents AEV 002 strain; curves 3-7 represent NDV CS2 strain, AIV H5N1 Re-6 strain, ALV RAV1 strain, MDV FC-126 strain and negative control respectively

detection, it does have its limitations. Specimens must be collected from fresh tissues, organs or blood and the virus must be inoculated and cultured in sensitive chicken embryos. Overall, virus isolation has been described as laborious with its difficult and timeconsuming process $(3,15)$. Cell culture for AEV is also difficult. Conventional methods, such as immunofluorescence assay which is performed on frozen brain sections, are typically used for detecting AEV. Therefore, diagnostic methods with higher sensitivity and specificity should be developed for the effective prevention of $\mathrm{AE}$ and for $\mathrm{AEV}$ surveillance.

Real-time RT-PCR is based on detecting and monitoring the amplification of template DNA by fluorescence. This technique has received widespread acceptance due to its higher sensitivity, lower risk of contamination and improved rapidity and multiplex ability (23). Furthermore, Real-time RT-PCR enables the precise quantitation of nucleic acids, which makes it indispensable in gene normal studies $(6,9)$. To further improve the ability to detect and quantitate low amounts of AEV, Real-time RT-PCR assay is developed. The assay utilizes TaqMan technology and fluorescent labeled probes and permits the detection of minimal viruses. To quantitate viral genomes, cDNA amplicons carrying the $\mathrm{T} 7$ promoter provided by the forward primer is directly used to produce viral RNA run-off transcript.

The development of a Real-time RT-PCR system is designed for the detection of AEV viruses. When tested, the design was shown to be specific. Namely AEV primers and probes only detected AEV RNA but not other virus RNA. The inability to detect NDV, AIV, MDV, ALV genomes indicated the specificity of this system further.

A remarkable advantage of Real-time RT-PCR is its quantitative capability, which allows the determination of virus load by establishing a congruent relationship 
that can be used to generate a standard curve. To obtain an accurate standard curve with the exact amplification efficiency as the viral genome, it is feasible to isolate a quantity of viruses that are sufficient to prepare a measurable genome. Another method is to prepare standard procedures by synthesizing run-off transcripts of viral RNA carrying the real-time amplicon. This method has exactly the same efficiency. The advantage of the system is that, the work load, time and resources are smaller, shorter and easier to get compared with the purification of large quantities of viruses. In addition, it is an optional and reliable way to quantitate viral RNA when the preparation of high quantities of virus is restricted due to the absence of a suitable cell system. We performed the amplification of T7 cDNA to prepare run-off transcripts of each virus to generate standard curves. Rather than cloning the amplified cDNA under the $\mathrm{T} 7$ promoter and then transcribing it (10), the current system used a cDNA fragment carrying the promoter for direct transcription, which could generate high quantities of viral RNA.

In this study, we established a novel Real-time RT-PCR system with higher sensitivity (coefficient of correlation $\mathrm{R}^{2}=0.987$, amplification efficiency $\mathrm{E}=1.0$, detection limit: $=20$ copies) than conventional RT-PCR. A total of 52 clinical samples were analyzed using this assay, and 33 samples were AEV positive, yielding an agreement rate of $91.2 \%$ with RT-PCR and $73.9 \%$ with a serological method. The detection results were highly consistent with the clinical findings (Tab. 3).

Compared with virus isolation/identification, chicken embryo sensitivity test, serological diagnostic methods and conventional PCR methods, quantitative fluorescence PCR is much more sensitive, efficient, and rapider. This system might be a promising alternative method for the diagnosis and prevention/control of AEV. To sum up, a high-throughput, specific and sensitive Real-time RT-PCR has been successfully developed and validated for the detection of AEV in clinical samples, which has important significance for clinical management and outbreak response of $\mathrm{AE}$ in the future.

\section{References}

1. Berger R. G.: An in vitro assay for quantifying the virus of avian encephalomyelitis. Avian Dis. 1982, 26, 534-541.

2. Bridges C. H., Flowers A. I.: Iridocyclitis and cataracts associated with an encephalomyelitis in chickens. J. Am. Vet. Med. Assoc. 1958, 132, 79-84.

3. Bülow $V$. V: Avian encephalomyelitis (AE). Cultivation, titration, and handling of the virus for live vaccines. Zen. Vet. 1965, 12, 298-311.

4. Bülow $V$. V.: Studies on the physico-chemical properties of the virus of avian encephalomyelitis (AE) with special reference to purification and preservation of virus suspensions. Zen. Vet. 1964, 11, 674-686.

5. Butterfield W. K., Helmboldt C. M., Luginbuhl R. E.: Studies on avian encephalomyelitis. IV. Early incidence and longevity of histopathologic lesions in chickens. Avian. Dis. 1969, 13, 53-57.

6. Buttitta F., Pellegrini C., Marchetti A., Gadducci A., Cosio S., Felicioni L., Barassi F., Salvatore S., Martella C., Coggi G., Bosari S.: Human telomerase reverse transcriptase mRNA expression assessed by real-time reverse trans- cription polymerase chain reaction predicts hemosensitivity in patients with ovarian carcinoma. J. Clin. Oncol. 2003, 21, 1320-1325.

7. Calnek B. W., Luginbuhl R. E., Helmboldt C. F.: Avian encephalomyelitis. Disease of Poultry. Iowa State Univ. Press, Ames, IA 1991, pp. 571-581.

8. Choi W. P., Miura S.: Indirect fluorescent antibody technique for the detection of avian encephalomyelitis antibody technique for the detection of avian encephalomyelitis antibody in chickens. Avian. Dis. 1972, 16, 949-951.

9. Egawa C., Miyoshi Y., Iwao K., Shiba E., Noguchi S.: Quantitative analysis of estrogen receptor-alpha and -beta messenger RNA expression in normal and malignant thyroid tissues by real-time polymerase chain reaction. Oncology 2001, 61, 293-298.

10. Fronhoffs S., Totzke G., Stier S., Wernert N., Rothe M., Bruning T., Koch B., Sachinidis A., Vetter H., Ko Y.: A method for the rapid construction of cRNA standard curves in quantitative real-time reverse transcription polymerase chain reaction. Mol. Cell. Probes. 2002, 16, 99-110.

11. Garrett J. K., Davis R. B., Ragland W. L.: Enzyme-linked immunosorbent assay for detection of antibody to avian encephalomyelitis virus in chickens. Avian. Dis. 1984, 28, 117-130.

12. Girshick T., Crary Jr. C. K.: Preparation of an agar gel precipitating antigen for avian encephalomyelitis and its use in evaluating the antibody status of poultry. Avian. Dis. 1982, 26, 798-804

13. Gosting L. H., Grinnell B. W., Matsumoto M.: Physico-chemical and morphological characteristics of avian encephalomyelitis virus. Vet. Microbiol. 1980, $5,87-100$

14. Heide L. V. D.: The fluorescent antibody technique in the diagnosis of avian encephalomyelitis. Univ. Manie. Tech. Bull. 1970, 44, 1-79.

15. Hoekstra J.: Expriments with avian encephalomyelitis. Br. Vet. J. 1964, 120 322-335.

16. Hohlstein W. M., Deshmukh D. R., Larsen C. T., Sautter J. H., Pomeroy B. S., MCDowell J. R.: An epiornithic of avian encephalomyelitis in turkeys. Am. J. Vet. Res. 1970, 31, 2233-2242.

17. Ikeda S.: Immunodiffusion tests in avian encephalomyelitis. II. Detection of precipitating antibody in infected chickens in comparison with neutralizing antibody. Natl. Inst. Anim. Health Q. 1977, 17, 88-94.

18. Jones E. E.: An encephalomyelitis in the chicken. Science 1932, 76, 331-332.

19. Jones E. E.: Epidemic tremor, an encephalomyelitis affecting young chickens. J. Exp. Med. 1934, 59, 781-798.

20. Li Z., Du Y., Wang S., Kang D.: Diagnostic report of avian encephalomyelitis in district of Qingdao. Ani. Qua. 1992, 2 (In Chinese).

21. Liu Q., Yang Z., Hao H., Cheng S., Fan W., Du E., Xiao S., Wang X., Zhang S. Development of a SYBR Green real-time RT-PCR assay for the detection of avian encephalomyelitis virus. J. Virol. Met. 2014, 206, 46-50.

22. Lukert P. D., Davis R. B.: New methods under investigation for the evaluation of the immune status of breeder hens to avian encephalomyelitis. II. Preliminary studies with an immunodiffusion test for avian encephalomyelitis antibodies. Avian. Dis. 1971, 15, 935-938

23. Mackay I. M., Arden K. E., Nitsche A.: Real-time PCR in virology. Nucleic. Acids. Res. 2002, 30, 1292-1305

24. Nicholas R. A. J., Ream A. J., Thornton D. H.: Replication of avian encephalomyelitis virus in chick embryo neuroglial cell cultures. Arch. Virol. 1987 96, 283-287.

25. Peckham M. C.: Case Report: Lens Opacities in Fowls Possibly Associated with Epidemic Tremors. Avian. Dis. 1957, 1, 247-255.

26. Roekel H. V., Bullis K. L., Clarke M. K.: Preliminary report on infectious avian encephalomyelitis. J. Am. Vet. Med. Assoc. 1938, 93, 382-375.

27. Roekel H. V., Bullis K. L., Clarke M. K.: Transmission of avian encephalomyelitis. J. Am. Vet. Med. Assoc. 1941, 99, 220.

28. Schaaf K., Lamoreaux W. F.: Control of avian encephalomyelitis by vaccination. Am. J. Vet. Res. 1955, 16, 627-633.

29. Smart J., Grix D. C.: Measurement of antibodies to infectious avian encephalomyelitis virus by ELISA. Avian. Pathol. 1985, 14, 341-352.

30. Summer F. W., Luginbuhl R. E., Jungherr E. L.: Studies on avian encephalomyelitis. II. Flock survey for embryo susceptibility to the virus. Am. J. Vet. Res. 1957, 18, 720-723.

31. Sytuo B., Matsumoto M.: Detection of chicken antibodies against avian encephalomyelitis virus by an enzyme-linked immunoassay. Poult. Sci. 1981 60, 1742.

32. Tannock G. A., Shafren D. R.: Avian encephalomyelitis: A review. Avian. Pathol. 1994, 23, 603-620.

Corresponding author: Dr. Zhongze Feng; e-mail: fengzhongze@126.com 